\title{
BMJ Open Factors associated with continued smoking after the diagnosis of type 2 diabetes: a retrospective study in the Korean cohort
}

\author{
Mi Hee Cho, ${ }^{1}$ Sung Min Kim, ${ }^{2}$ Kiheon Lee, ${ }^{3,4}$ Sang Min Park, ${ }^{1,2}$ Jooyoung Chang, ${ }^{2}$ \\ Seulggie Choi, ${ }^{2}$ Kyuwoong Kim, ${ }^{2}$ Hye-Yeon Koo, ${ }^{3} \mathrm{Ji}-\mathrm{Hye} \mathrm{Jun}^{3}$
}

To cite: Cho MH, Kim SM, Lee $\mathrm{K}$, et al. Factors associated with continued smoking after the diagnosis of type 2 diabetes: a retrospective study in the Korean cohort. BMJ Open 2018;8:e020160. doi:10.1136/ bmjopen-2017-020160

- Prepublication history for this paper is available online. To view these files, please visit the journal online (http://dx.doi org/10.1136/bmjopen-2017020160).

Received 18 0ctober 2017 Revised 12 March 2018 Accepted 4 June 2018

\section{Check for updates}

${ }^{1}$ Department of Family Medicine, Seoul National University Hospital, Seoul, Republic of Korea

${ }^{2}$ Department of Biomedical Sciences, Seoul National University Graduate School, Seoul, Republic of Korea

${ }^{3}$ Department of Family Medicine, Seoul National University Bundang Hospital, Seongnam-si, Gyeonggi-do, Republic of Korea ${ }^{4}$ Department of Family Medicine, College of Medicine, Seoul National University, Seoul, Republic of Korea

Correspondence to

Dr Kiheon Lee;

keyhoney@gmail.com

\section{ABSTRACT}

Objective To investigate the factors associated with continued smoking in patients newly diagnosed with type 2 diabetes.

Design Retrospective study using the Korean National Health Insurance Service-National Health Screening Cohort (2002-2013) database.

Participants Male patients newly diagnosed with type 2 diabetes between 1 January 2004 and 31 December 2011.

Measurement Change in smoking behaviour after the diabetes diagnosis was assessed using a self-reported questionnaire, which was administered before and after the diagnosis. To identify the factors associated with continued smoking after diabetes diagnosis, a multivariate-adjusted logistic regression was conducted using only the variables with statistical significance from the univariate analyses.

Results Younger age, lower economic status, heavier smoking habit, lower Charlson Comorbidity Index and comorbid hypertension were identified as factors associated with continued smoking after the diagnosis of type 2 diabetes. Older patients (adjusted OR (aOR) $0.71,95 \% \mathrm{Cl} 0.63$ to 0.79 ) and patients with longer diabetic duration (1-2 years $0 \mathrm{R} 0.88,95 \% \mathrm{Cl} 0.80$ to 0.98 , $\geq 3$ years $0 \mathrm{R} 0.63,95 \% \mathrm{Cl} 0.55$ to 0.73 ) were more likely to quit smoking. Contrastingly, smokers in the lower economic status (aOR $1.29,95 \% \mathrm{Cl} 1.18$ to 1.42) and heavier smoking habit (moderate: aOR $1.53,95 \% \mathrm{Cl}$ 1.35 to 1.72 ; heavy: aOR $1.90,95 \% \mathrm{Cl} 1.67$ to 2.17 ) categories were more likely to continue smoking after the diagnosis.

Conclusions It is important to identify the factors associated with smoking behaviour in patients with type 2 diabetes. Recognising the factors that contribute to the vulnerability of patients to continued smoking will be helpful in developing policies and intervention strategies in future. Vulnerable patients may require intensive education and encouragement to quit smoking. We recommend physicians to take a more proactive approach, such as encouraging frequent clinical sessions for behavioural counselling and even early pharmacological interventions, when they encounter patients with the factors outlined in this study.
Strengths and limitations of this study

- This study extensively evaluated various factors related to continued smoking after diabetes diagnosis using a large national cohort database that provided health examination data, medical information and demographic information of nearly 510000 Koreans aged between 40 and 79 years.

- This retrospective cohort study investigated the factors related to changes in smoking habit before and after diabetes diagnosis via a longitudinal study design rather than a cross-sectional study design.

- Change in smoking habit after diabetes diagnosis was assessed by comparing the answers with a self-reported questionnaire before and after the diagnosis without biochemical verification, which may have resulted in an overestimation of the rate of smoking cessation in this study.

\section{INTRODUCTION}

Smoking cessation in the general population has been shown to have immediate and long-term health benefits. ${ }^{1-4}$ Smoking alone is considered as a modifiable risk factor for cardiovascular diseases (CVDs) and certain types of cancers associated with premature death worldwide. ${ }^{24-7}$ Moreover, smoking may increase the risk of developing type 2 diabetes in the general population ${ }^{8-10}$ and increase the risk of mortality, cardiovascular events ${ }^{112}$ and microvascular complications ${ }^{13-15}$ in patients with diabetes. Thus, many clinical guidelines for managing diabetes, such as the American Diabetes Association guidelines and the National Institute for Health and Care Excellence guidelines, have strongly recommended smoking cessation in patients with diabetes to improve health outcomes. ${ }^{16-18}$ However, although patients newly diagnosed with chronic diseases are usually motivated, at least initially, to seek healthier lifestyles, such as quit smoking and decrease alcohol 
consumption, the smoking rate among patients diagnosed with diabetes has remained unchanged. ${ }^{18} 19$

There have been tremendous efforts to decrease the smoking rate worldwide, including public education about health risks of smoking and implementation of national health policies. While such efforts have been successful in many countries, ${ }^{20-22}$ they have not been successful in many Asian countries, including South Korea. Currently, the smoking rate is slightly over $30 \%$ among adult Korean men, which is one of the highest rates in the world.$^{23}$ Despite the increased death rate attributed to CVDs, there has not been a substantial decrease in the prevalence of smoking. ${ }^{23-25}$ Factors related to the success or failure of smoking cessation have been investigated in many previous studies; however, most of these studies were from Western countries. ${ }^{26-30}$ Characteristics of smokers and patterns of smoking may vary drastically from country to country due to different socioeconomic statuses, cultural atmospheres and smoking policies. ${ }^{26-31}$ For example, it has previously been reported that age is a predictor of smoking cessation that varies greatly across different geographic locations; younger smokers were more likely to quit smoking in Western countries, whereas older smokers were more likely to quit in Asian countries. ${ }^{29} 31$ Therefore, it would be important to identify unique characteristics that dictate smoking behaviour in each country to develop more culture-specific and region-specific intervention strategies.

The prevalence of diabetes in Korea is higher than the average prevalence of diabetes among the Organisation for Economic Cooperation and Development countries, according to a recent report by the Korean Diabetes Association. ${ }^{32}$ However, there has not been any study focusing on identifying the factors associated with continued smoking in patients with type 2 diabetes in Asian countries. Here, we aim to identify the factors associated with continued smoking among patients newly diagnosed with type 2 diabetes using a national cohort database. We expect the factors identified in this study to contribute to the development of future intervention strategies and policies that better promote smoking cessation in patients with type 2 diabetes.

\section{METHODS}

\section{Study population}

This study was conducted using the Korean National Health Insurance Service-National Health Screening Cohort (2002-2013) (NHIS-HealS), which was generated from the national health screening database of the Korean National Health Insurance Service (NHIS). Since 1989, NHIS has been providing mandatory health insurance to nearly $97 \%$ of the entire Korean population. ${ }^{33}$ Beneficiaries older than 40 years of age are required to participate in the national health screening programme (NHSP) biennially. ${ }^{34}$ Those who are eligible to participate in NHSP can receive health screening anytime between February and December in the year. In addition, on completion of

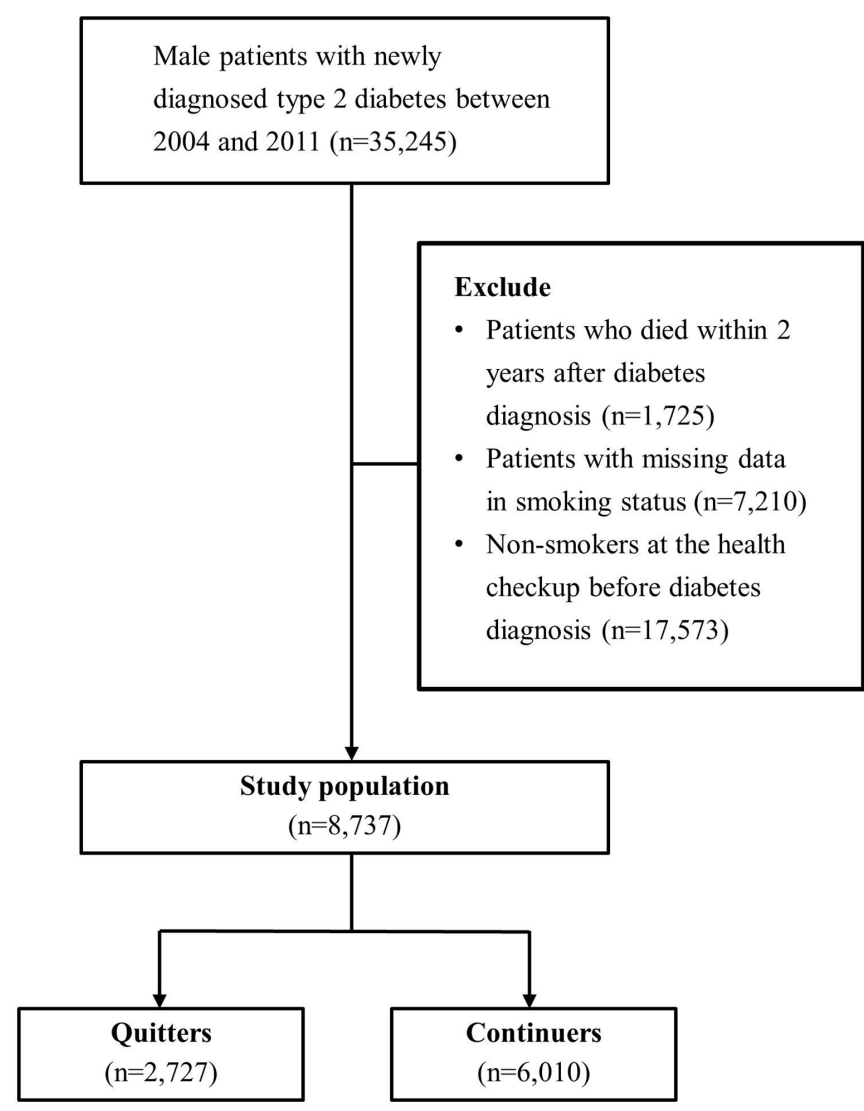

Figure 1 Study population. Smoking status data came from the Korean National Health Insurance Service's National health screening data of smoking questionnaires.

the health screening, beneficiaries are required to submit a completed questionnaire on the day of the check-up. NHIS-HealS database contains randomly selected $10 \%$ of the beneficiaries who participated in NHSP between 2002 and 2003, providing all sociodemographic and clinical follow-up data from health screenings that took place until 2013. Clinical data included clinical facilities visits, claimed diagnosis records based on International Classification of Disease (ICD) codes and other medical data. Sociodemographic data included age, sex, income status, residence information and disability status.

Newly diagnosed patients were defined using the ICD-10 codes for type 2 diabetes (E11, E12 and E14). To be considered new patients with diabetes, they must not have any records of these codes prior to 2004; any visits to hospitals for diabetes-related codes must be after 1 January 2004. Among them, only patients with at least one additional claimed record of diabetes-related codes within a year were included to enhance the accuracy of 'new diabetes diagnosis' in the study population.

A total of 35245 men in the NHIS-HealS database were identified as patients newly diagnosed with type 2 diabetes between 1 January 2004 and 31 December 2011 (figure 1). Patients who died within 2 years from diagnosis $(n=1725)$ and those who did not participate in the NHSP at least once each before and after the diagnosis $(n=7210)$ were excluded. Moreover, participants who 


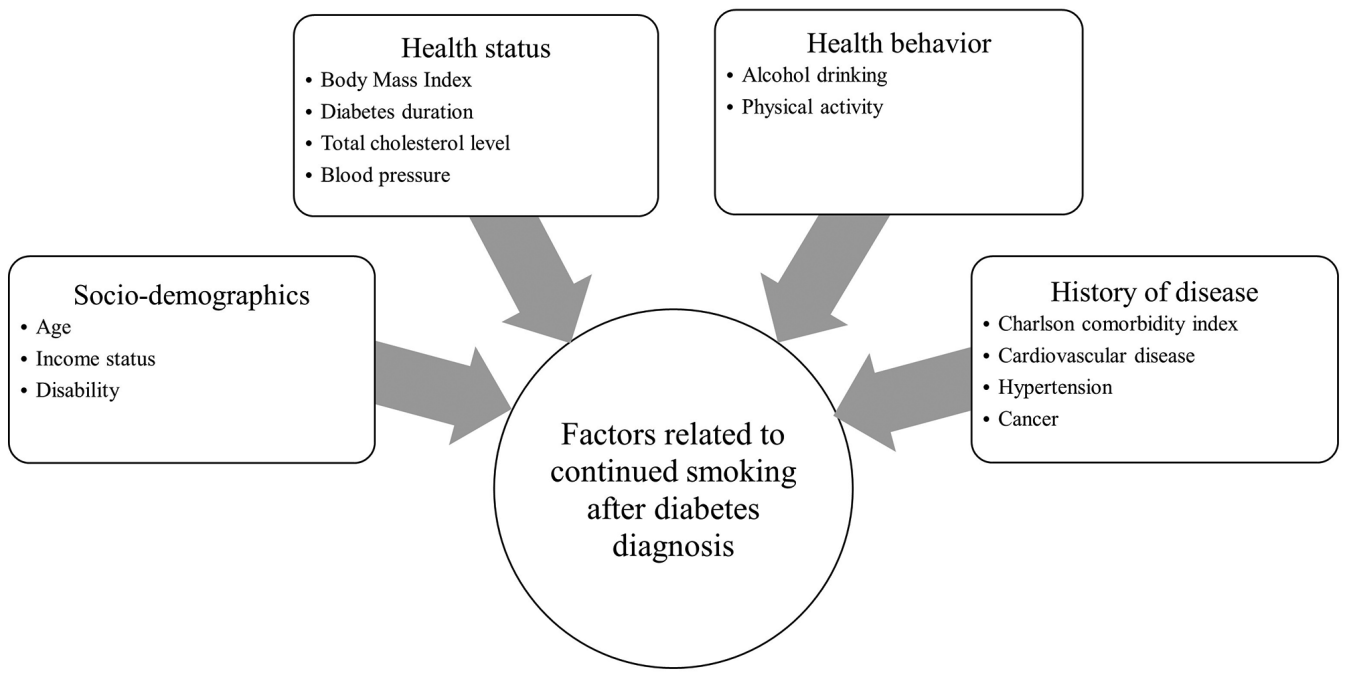

Figure 2 Categorisation of variables associated with smoking or type 2 diabetes.

were non-smokers at the time of health examination before diabetes diagnosis $(\mathrm{n}=17573)$ were also excluded. Thus, a final number of 8737 smokers who smoked before the onset of diabetes and met these criteria were included for final analysis (figure 1).

The requirement of informed consents was waived due to the anonymity of the data obtained from NHIS. All experiments were conducted in accordance with the relevant guidelines and regulations.

\section{Patient and public involvement}

Patients and/or public were not involved in the design of the study.

\section{Variables and outcome}

Study variables were categorised into four domains: the sociodemographic domain (age, income status and disability), health status domain (body mass index (BMI), diabetes duration, total cholesterol level and blood pressure level), health behaviour domain (smoking amount per day, alcohol consumption and physical activity) and history of disease domain (Charlson Comorbidity Index (CCI), heart disease, stroke, hypertension and cancer) (figure 2). Each variable, except diabetes duration, was obtained from the health screening data taken before the diagnosis. Diabetes duration was calculated by measuring the number of days from the date of diabetes diagnosis to the date of the health examination after diabetes diagnosis. Income status was originally provided as deciles of income level, based on the NHIS's insurance premium, and divided into two groups (low and high). Disability was based on the classification code for the specific disability type according to the NHIS's database. Smoking amount (cigarettes per day) was categorised into three groups: light (1-9 cigarettes/day), moderate (10-19 cigarettes/ day) and heavy ( $\geq 20$ cigarettes/day).${ }^{35}$ History of diseases, including heart disease, stroke, hypertension and cancer, was based on a self-reported answer from the health screening questionnaire taken before the diagnosis.
Change in smoking behaviour was assessed using the self-reported questionnaire of the NHIS health check-up. By comparing the answers from the smoking habit questionnaire, taken before and after the diagnosis of diabetes, patients were divided into two groups: the quitters and the continuers. The quitters included patients who identified themselves as a current smoker before the diagnosis of diabetes, but as an ex-smoker after the diagnosis. The continuers included patients who identified themselves as a current smoker before and after the diagnosis.

\section{Statistical analysis}

Logistic regression analyses were performed to obtain the ORs with $95 \%$ CIs of continued smoking. First, univariate analyses were performed for each variable. Then, multivariate analysis was conducted to find factors related to continued smoking using variables with statistical significance in univariate analyses. All data mining and statistical analyses of this study were conducted using SAS 9.4 (SAS Institute, Cary, North Carolina, USA) and STATA 13.0 (StataCorp LP, College Station, Texas, USA).

\section{RESULTS}

The baseline characteristics of study participants after the diagnosis are described in table 1 . The prevalence of smoking cessation after the diagnosis was $31.2 \%$ $(n=2727)$. The mean age of patients with a new diagnosis of diabetes was 52.6 years.

The results of univariate and multivariate analyses for each variable are presented in table 2 . In univariate analysis, age (OR $0.66,95 \%$ CI 0.59 to 0.74 ), diabetes duration ( $1-2$ years OR $0.86,95 \%$ CI 0.78 to $0.95, \geq 3$ years OR 0.63 , $95 \%$ CI 0.55 to 0.73 ), income status (OR $1.24,95 \%$ CI 1.13 to 1.36 ), smoking amounts (moderate OR $1.61,95 \% \mathrm{CI}$ 1.43 to 1.81 , heavy OR $2.07,95 \%$ CI 1.82 to 2.35$)$, CCI (OR $0.85,95 \%$ CI 0.77 to 0.93 ) and hypertension (OR 1.16, $95 \%$ CI 1.03 to 1.29 ) were statistically different between 
Table 1 Baseline characteristics of the study population

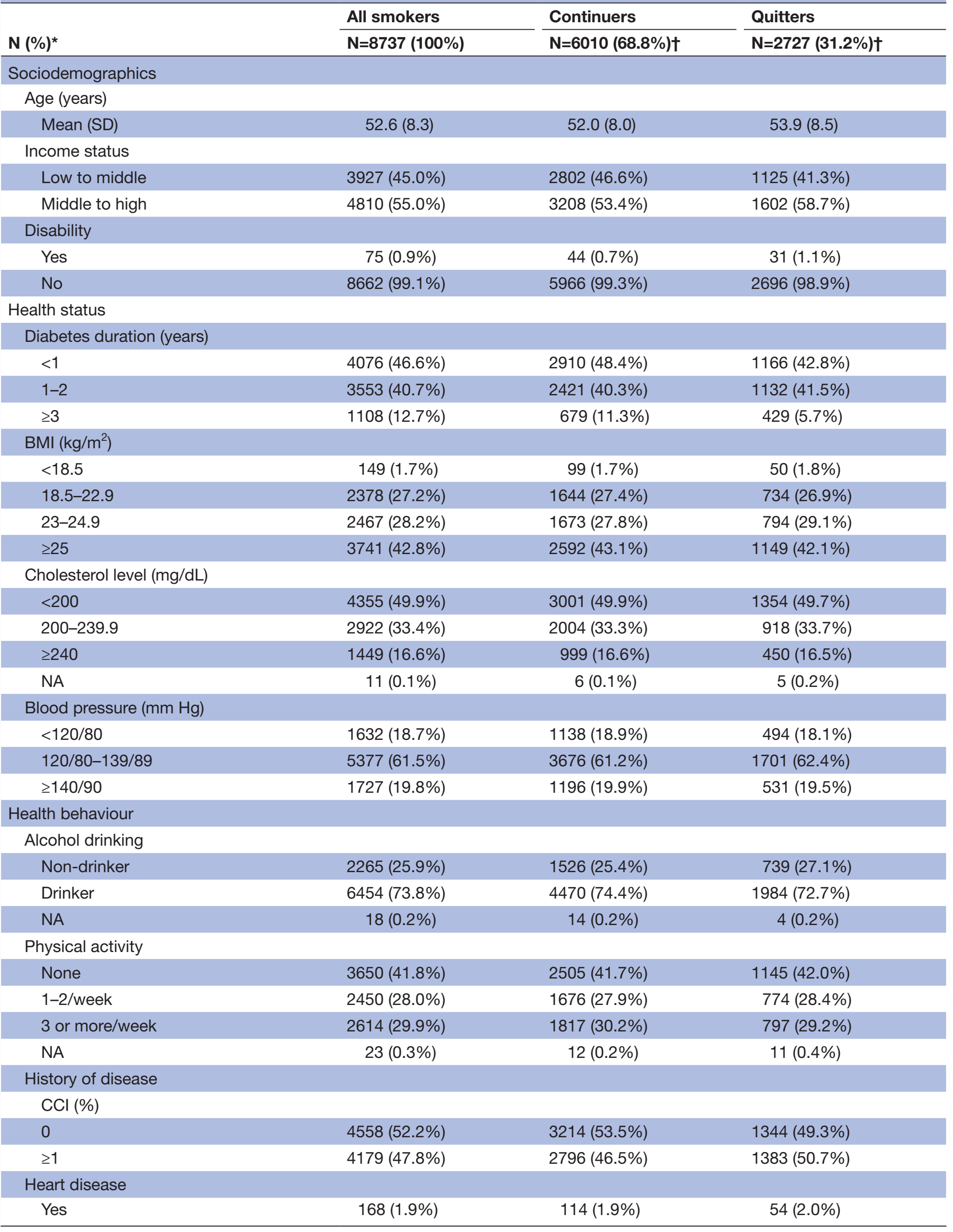

Continued 
Table 1 Continued

\begin{tabular}{|c|c|c|c|}
\hline & All smokers & Continuers & Quitters \\
\hline $\mathbf{N}(\%)^{*}$ & $\mathrm{~N}=8737(100 \%)$ & $\mathrm{N}=6010(68.8 \%) \dagger$ & $\mathrm{N}=2727(31.2 \%) \dagger$ \\
\hline No & 8569 (98.1\%) & $5896(98.1 \%)$ & 2673 (98.0\%) \\
\hline \multicolumn{4}{|c|}{ Stroke } \\
\hline Yes & $59(0.7 \%)$ & $37(0.6 \%)$ & $22(0.8 \%)$ \\
\hline No & 8678 (99.3\%) & 5973 (99.4\%) & 2705 (99.2\%) \\
\hline \multicolumn{4}{|c|}{ Hypertension } \\
\hline Yes & $1820(20.8 \%)$ & 1296 (21.6\%) & 524 (19.2\%) \\
\hline No & 6917 (79.2\%) & 4714 (78.4\%) & 2203 (80.8\%) \\
\hline \multicolumn{4}{|c|}{ Cancer } \\
\hline Yes & $122(1.4 \%)$ & $83(1.4 \%)$ & $39(1.4 \%)$ \\
\hline No & 8615 (98.6\%) & 5927 (98.6\%) & 2688 (98.6\%) \\
\hline
\end{tabular}

${ }^{*}$ Column percentage.

†Row percentage.

$\mathrm{BMI}$, body mass index; $\mathrm{CCl}$, Charlson Comorbidity Index.

the quitters and continuers. In the multivariate-adjusted analyses, older patients were more likely to quit after the diagnosis than younger patients (adjusted OR, aOR 0.71, $95 \%$ CI 0.63 to 0.79 ). Diabetes duration was negatively associated with continued smoking (1-2 years OR 0.88 , $95 \%$ CI 0.80 to $0.98, \geq 3$ years OR $0.63,95 \%$ CI 0.55 to 0.73). Moreover, smokers with a higher CCI score were more likely to quit after the diagnosis than those with a low CCI score (aOR $0.87,95 \%$ CI 0.79 to 0.96 ). In contrast, patients with lower income status (aOR 1.29, 95\% CI 1.18 to 1.42 ), greater smoking amount (moderate aOR 1.53, $95 \%$ CI 1.35 to 1.72 ; heavy aOR $1.90,95 \%$ CI 1.67 to 2.17 ) and comorbid hypertension (aOR 1.25, 95\% CI 1.11 to 1.41) were more likely to continue smoking after the diagnosis than their counterparts.

\section{DISCUSSION}

This study investigated the prevalence of smoking cessation and factors for continued smoking in patients newly diagnosed with type 2 diabetes using a large national sample cohort. Despite the high prevalence of diabetes and smoking in Asian countries, to the best of our knowledge, there have not been any studies identifying factors associated with changes in smoking habit among patients with diabetes. It is known that patterns of smoking and smoking cessation vary depending on the specific population, such as diabetic population and cancer survivor population, as well as in different countries due to different national smoking cessation policies and/or social and cultural atmospheres regarding smoking. As such, it is important to identify factors related to continued smoking that are specific to a particular population to develop more effective intervention strategies and policies that encourage smoking cessation.

This nationwide retrospective study investigated four domains of factors: health status (diabetes duration,
BMI, total cholesterol level and blood pressure), health behaviour (smoking status, alcohol consumption and physical activity), sociodemographic domain (age, income status and disability) and history of disease (CCI, heart disease, stroke, hypertension and cancer). Except the health status domain, previous studies regarded the other three domains to be related to smoking habit change in the general population. Factors that were found to be statistically associated with continued smoking in our univariate analyses were younger age, low-income status, higher smoking amount per day, no comorbidities and comorbid hypertension, which were still statistically significant factors related to continued smoking after the diagnosis of diabetes in our multivariate analyses.

In many previous studies, age has been identified as one of the factors related to smoking cessation, although the direction of association was inconsistent. ${ }^{29-31} 36-38$ Interestingly, studies conducted in Western countries found a negative or no association between age and smoking cession. ${ }^{29} 3738$ Contrastingly, studies conducted in Asia reported a positive association between these two factors. ${ }^{31}{ }^{36}$ Our findings are consistent with previous Asian reports. A cross-sectional study conducted in Korea reported that elderly smokers showed greater intention to quit smoking than younger smokers in the general population. ${ }^{39}$ This discrepancy regarding age between Korea and Western countries may be explained by cultural and social differences between the two populations; it is a common practice in Korea for elderly patients to live with younger generations, given the roots of Confucianism and its teachings of filial piety. Given such living arrangements, it is likely that once diagnosed with a chronic illness, elderly patients are strictly monitored and forced to lead a healthier lifestyle from their children, resulting in negative association between age and continued smoking. 
Table 2 The results of univariate and multivariate-adjusted analyses for associated factors with continued smoking after type 2 diabetes diagnosis

\section{Continued smoking}

\begin{tabular}{|c|c|c|c|}
\hline & & & \\
\hline & \multirow[b]{2}{*}{ N (\%) } & \multirow{2}{*}{$\begin{array}{l}\text { Univariate } \\
\text { OR }(95 \% \mathrm{Cl})\end{array}$} & \multirow{2}{*}{$\begin{array}{l}\text { Multivariate } \\
\text { aOR }(95 \% \mathrm{Cl})\end{array}$} \\
\hline & & & \\
\hline \multicolumn{4}{|l|}{ Sociodemographics } \\
\hline \multicolumn{4}{|l|}{ Age (years) } \\
\hline 40-64 & $4869(81.0 \%)$ & 1.00 & 1.00 \\
\hline $65-80$ & $1141(19.0 \%)$ & $0.66^{\star}(0.59$ to 0.74$)$ & $0.71^{*}(0.64$ to 0.80$)$ \\
\hline \multicolumn{4}{|l|}{ Income status } \\
\hline High & 3208 (53.4\%) & 1.00 & 1.00 \\
\hline Low & $2802(46.6 \%)$ & $1.24^{\star}(1.13$ to 1.36$)$ & $1.30 *(1.19$ to 1.43$)$ \\
\hline \multicolumn{4}{|l|}{ Disability } \\
\hline No & $5966(99.3 \%)$ & 1.00 & \\
\hline Yes & 44 (0.7\%) & 0.64 (0.40 to 1.02$)$ & \\
\hline \multicolumn{4}{|l|}{ Health status } \\
\hline \multicolumn{4}{|c|}{ Diabetes duration (years) } \\
\hline$<1$ & $2910(48.4 \%)$ & 1.00 & 1.00 \\
\hline $1-2$ & $2421(40.3 \%)$ & $0.86^{\star}(0.78$ to 0.95$)$ & $0.88^{\star}(0.80$ to 0.98$)$ \\
\hline$\geq 3$ & $679(11.3 \%)$ & $0.63^{\star}(0.55$ to 0.73$)$ & $0.63^{\star}(0.55$ to 0.73$)$ \\
\hline \multicolumn{4}{|l|}{$\mathrm{BMI}\left(\mathrm{kg} / \mathrm{m}^{2}\right)$} \\
\hline$<25$ & $3416(56.9 \%)$ & 1.00 & \\
\hline$\geq 25$ & $2592(43.1 \%)$ & 1.04 (0.95 to 1.14$)$ & \\
\hline \multicolumn{4}{|c|}{ Cholesterol level (mg/dL) } \\
\hline$<200$ & 3001 (50.0\%) & 1.00 & \\
\hline$\geq 200$ & $3003(50.0 \%)$ & 0.99 (0.90 to 1.08$)$ & \\
\hline \multicolumn{4}{|c|}{ Blood pressure $(\mathrm{mm} \mathrm{Hg})$} \\
\hline$<140 / 90$ & 4814 (80.1\%) & 1.00 & \\
\hline$\geq 140 / 90$ & $1196(19.9 \%)$ & 1.03 (0.92 to 1.15$)$ & \\
\hline \multicolumn{4}{|l|}{ Health behaviour } \\
\hline \multicolumn{4}{|c|}{ Smoking (cigarettes/day) } \\
\hline Light (1-9) & $953(15.9 \%)$ & 1.00 & 1.00 \\
\hline Moderate (10-19) & $2901(48.3 \%)$ & $1.61^{\star}(1.43$ to 1.81$)$ & $1.52^{*}(1.35$ to 1.72$)$ \\
\hline Heavy $(\geq 20)$ & 2156 (35.9\%) & $2.07^{\star}(1.82$ to 2.35$)$ & $1.89^{*}(1.66$ to 2.16$)$ \\
\hline \multicolumn{4}{|l|}{ Alcohol drinking } \\
\hline Non-drinker & $1526(25.4 \%)$ & 1.00 & \\
\hline Drinker & $4470(74.6 \%)$ & 1.09 (0.98 to 1.21$)$ & \\
\hline \multicolumn{4}{|l|}{ Physical activity } \\
\hline Yes & $3493(58.2 \%)$ & 1.00 & \\
\hline No & 2505 (41.8\%) & 0.98 (0.90 to 1.08$)$ & \\
\hline \multicolumn{4}{|l|}{ History of disease } \\
\hline \multicolumn{4}{|l|}{$\mathrm{CCl}(\%)$} \\
\hline 0 & 3214 (53.5\%) & 1.00 & 1.00 \\
\hline$\geq 1$ & $2796(46.5 \%)$ & $0.85^{\star}(0.77$ to 0.93$)$ & $0.88^{*}(0.80$ to 0.96$)$ \\
\hline \multicolumn{4}{|l|}{ Heart disease } \\
\hline No & $5896(98.1 \%)$ & 1.00 & \\
\hline Yes & 114 (1.9\%) & 0.96 (0.69 to 1.33$)$ & \\
\hline
\end{tabular}


Continued smoking

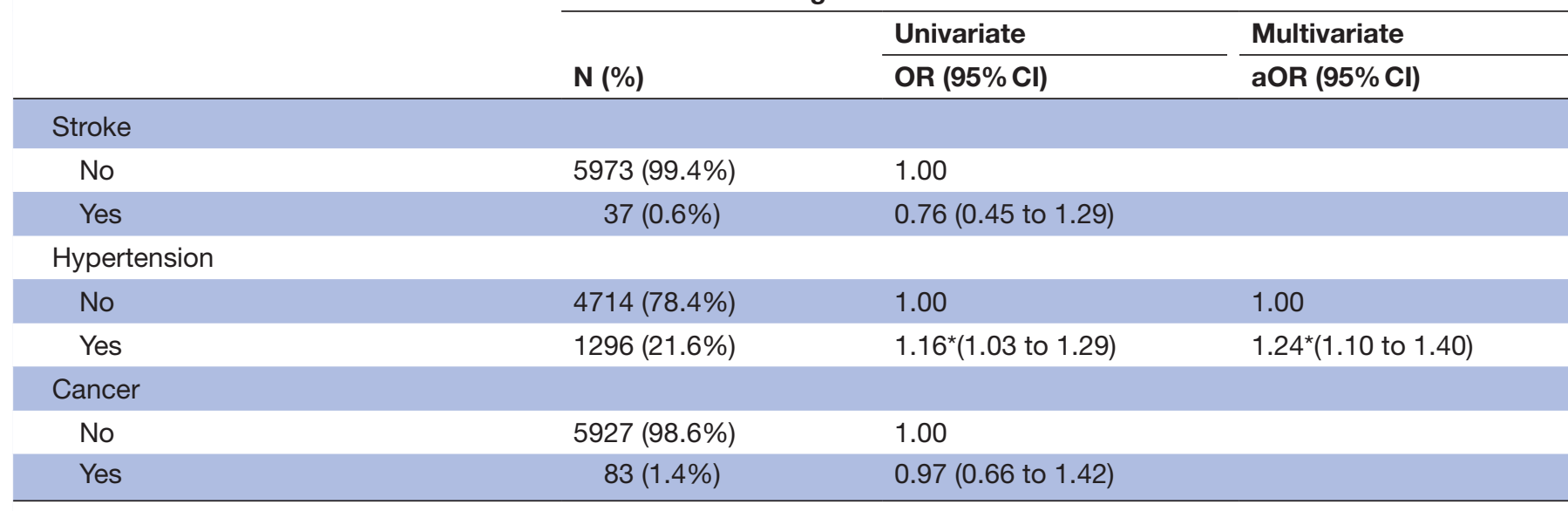

${ }^{*} \mathrm{P}<0.05$.

aOR, adjusted OR; BMI, body mass index; CCl, Charlson Comorbidity Index.

Consistent with previous studies, we also found a negative association between diabetes duration and continued smoking among new patients with diabetes. ${ }^{40}$ Longer disease duration alone may motivate patients to quit smoking. Moreover, with increased duration of diabetes, patients would likely have been exposed to repeated encouragement to quit smoking from their physicians and loved ones, resulting in higher prevalence of smoking cessation among those with longer diabetes duration.

An interesting finding in this study is that newly diagnosed patients with diabetes in the low-income group were more likely to continue smoking. In previous studies, association of continued smoking with socioeconomic status in the general population has been inconsistent, showing high variance between countries. ${ }^{26}{ }^{36}{ }^{41}$ Such inconsistencies are expected, since the impact of income level on smoking behaviour may depend on the level of economic development in each country. Negative association between income level and continued smoking in Korea may have an interesting implication for the development of antismoking policy. Combined with a national policy to increase cigarettes prices and taxes, it would be an effective strategy to provide subsidies for pharmacological smoking cessation treatments for patients with diabetes with low income.

A positive association between continued smoking and smoking amount per day in this study is consistent with previous studies. ${ }^{31} 3641$ Higher smoking amount per day indicates heavier nicotine dependence, resulting in increased likelihood of continued smoking. In addition, the finding that patients with comorbidities were more likely to quit smoking after the diagnosis of diabetes is consistent with a previous cross-sectional study in Korea. ${ }^{39}$ It can be easily speculated that patients with predisposing comorbidities may pursue healthier lifestyle when diagnosed with an additional chronic disease, like diabetes. This may be the case because it is common knowledge that smoking induces adverse health effects and because these patients received intense, repeated education about the benefits of smoking cessation.

An unexpected finding regarding the association between the change in smoking habit and comorbidities in this study was that patients with predisposing hypertension, who were newly diagnosed with diabetes, showed a higher tendency to continue smoking. This finding was not observed in previous studies. Comorbidities of hypertension and diabetes increase the risk of CVDs, compared with just having either one of these diseases; hence, adverse effects of smoking in patients with both chronic diseases will result in compounded consequences. ${ }^{42}$ Therefore, a further study is necessary to confirm whether this finding can be reproduced in the general population or in other specific populations in Korea.

A strength of this study is that, to the best of our knowledge, this is the first study to identify the factors associated with continued smoking in patients newly diagnosed with diabetes in an Asian country. Another strength is that this research was conducted using a large national cohort sample with the administrative database. Despite its strengths, however, there are several limitations to this study. First, since the national cohort used in this study was randomly sampled among those who voluntarily attended the biannual NHSP, with at least two visitations during the follow-up period, there may be selection bias. In other words, those included in this study may likely be more attentive to their health, which in turn suggests that they may more likely be motivated to quit smoking when diagnosed with diabetes, compared with the general population. The rate of smoking cessation after the diagnosis in this study was $31.3 \%$, which could be an overestimation due to this selection bias, suggesting that a higher portion of patients in reality may continue to smoke after the diagnosis of diabetes. Second, the change in smoking behaviour was assessed using only the information within the database; hence, subsequent changes in smoking status, such as resuming smoking, as well as the status in between 
exams were not evaluated. To improve long-term health outcomes, continued smoking cessation is critical; however, only a small portion of those who quit smoking succeed in maintaining a complete smoke-free lifestyle. ${ }^{29} 43$ It is important to recognise that there are differences between factors that influence attempts to quit smoking and factors that influence-and allow for successful-continued smoking cessation; hence, it is critical to identify both varieties of factors for the purpose of developing effective policies conducive to cessation and continued cessation. ${ }^{29} 3038$ Therefore, future research is needed in this area. Third, the change in smoking habit shown in this study was assessed using only the patient-answered questionnaire without biochemical verification of smoking status, such as urine cotinine and breath carbon monoxide monitoring. This may have resulted in an overestimation of the rate of smoking cessation in this study. Fourth, due to the nature of the administrative database used in this study, detailed information about the sociodemographic factors, such as marital status and family's smoking habit, was limited. It has been reported that living with a smoker was one of the risk factors associated with persistent smoking in the general population. ${ }^{44}{ }^{45}$ Hence, a future study is necessary to further investigate the role of sociodemographic factors in smoking habit. Another limitation is that this study included only male patients, since the prevalence of smoking in the Korean female population presented in the cohort database was low $(2.5 \%)$. A systematic review reported that the risk of coronary heart disease is significantly higher in female smokers with diabetes than in male smokers with diabetes ${ }^{46}$; therefore, a future research about the factors associated with smoking habit in diabetic women should also be conducted.

In conclusion, the factors associated with continued smoking in patients newly diagnosed with type 2 diabetes were identified in this study. Our findings can contribute to future intervention strategies and policies by improving the recognition of patients vulnerable to continued smoking. The important clinical implication of this study is that physicians should strongly advise smoking cessation to patients who possess the characteristics reported in this study and consider customised strategies for each vulnerable group to encourage smoking cessation. For example, to younger patients with diabetes, physicians should emphasise the longterm health risks of smoking, such as cardiovascular and chronic respiratory diseases. Moreover, physicians should consider more extensive interventions, such as having frequent clinical sessions for intensive behavioural counselling as well as early pharmacological intervention.

Acknowledgements We would like to thank Hyeyoung Yoo for providing administrative support. This study used the National Health Insurance ServiceNational Health Screening Cohort data [NHIS-2017-2-471], which were prepared by the Korean National Health Insurance Service.

Contributors MHC, the co-first author, designed the experiments, interpreted the results of data analysis and drafted the manuscript. SMK, the co-first author, designed the experiments, performed the data analysis and drafted the manuscript.
$\mathrm{KL}$, the corresponding author, advised to interpret the results of analysis and to revise the manuscript. SMP advised to design the analysis and to interpret the results of analysis, JC performed the data mining for the analysis, SC, KK, H-YK and $\mathrm{J}$-HJ participated in the idea discussion and reviewed the manuscript. All authors reviewed the manuscript.

Funding The authors have not declared a specific grant for this research from any funding agency in the public, commercial or not-for-profit sectors.

Competing interests None declared.

Patient consent Not required.

Ethics approval The study was approved by the Seoul National University Bundang Hospital Institutional Review Board [No. X-1701/378-902].

Provenance and peer review Not commissioned; externally peer reviewed. Data sharing statement No additional data available.

Open access This is an open access article distributed in accordance with the Creative Commons Attribution Non Commercial (CC BY-NC 4.0) license, which permits others to distribute, remix, adapt, build upon this work non-commercially, and license their derivative works on different terms, provided the original work is properly cited and the use is non-commercial. See: http://creativecommons.org/ licenses/by-nc/4.0/

(c) Article author(s) (or their employer(s) unless otherwise stated in the text of the article) 2018. All rights reserved. No commercial use is permitted unless otherwise expressly granted.

\section{REFERENCES}

1. US Department of Health and Human Services. The health benefits of smoking cessation (DHHS Publication No CDC 90-8416). Washington, DC: US Government Printing Office, 1990.

2. Jha P, Ramasundarahettige C, Landsman V, et al. 21st-century hazards of smoking and benefits of cessation in the United States. $N$ Engl J Med 2013;368:341-50.

3. Doll R, Peto R, Boreham J, et al. Mortality in relation to smoking: 50 years' observations on male British doctors. BMJ 2004;328:1519.

4. Mons U, Müezzinler A, Gellert C, et al. Impact of smoking and smoking cessation on cardiovascular events and mortality among older adults: meta-analysis of individual participant data from prospective cohort studies of the CHANCES consortium. BMJ 2015;350:h1551.

5. Godtfredsen NS, Holst C, Prescott E, et al. Smoking reduction, smoking cessation, and mortality: a 16-year follow-up of 19,732 men and women from The Copenhagen Centre for Prospective Population Studies. Am J Epidemiol 2002;156:994-1001.

6. Jha P. Avoidable global cancer deaths and total deaths from smoking. Nat Rev Cancer 2009;9:655-64.

7. Villablanca AC, McDonald JM, Rutledge JC. Smoking and cardiovascular disease. Clin Chest Med 2000;21:159-72.

8. Willi C, Bodenmann P, Ghali WA, et al. Active smoking and the risk of type 2 diabetes: a systematic review and meta-analysis. JAMA 2007;298:2654-64.

9. Eyre H, Kahn R, Robertson RM, et al. Preventing cancer, cardiovascular disease, and diabetes: a common agenda for the American Cancer Society, the American Diabetes Association, and the American Heart Association. Circulation 2004;109:3244-55.

10. Akter S, Okazaki H, Kuwahara K, et al. Smoking, smoking cessation, and the risk of type 2 diabetes among Japanese adults: Japan epidemiology collaboration on occupational health study. PLoS One 2015;10:e0132166.

11. Yeh HC, Duncan BB, Schmidt MI, et al. Smoking, smoking cessation, and risk for type 2 diabetes mellitus: a cohort study. Ann Intern Med 2010;152:10-17.

12. Eliasson B. Cigarette smoking and diabetes. Prog Cardiovasc Dis 2003;45:405-13.

13. Śliwińska-Mosson $M$, Milnerowicz $H$. The impact of smoking on the development of diabetes and its complications. Diab Vasc Dis Res 2017;14:265-76.

14. Al-Rubeaan $\mathrm{K}$, Youssef AM, Subhani SN, et al. Diabetic nephropathy and its risk factors in a society with a type 2 diabetes epidemic: a Saudi National Diabetes Registry-based study. PLoS One 2014;9:e88956.

15. Gambaro G, Bax G, Fusaro M, et al. Cigarette smoking is a risk factor for nephropathy and its progression in type 2 diabetes mellitus. Diabetes Nutr Metab 2001;14:337-42.

16. American Diabetes Association. Standards of medical care in diabetes-2017. Diabetes Care 2017;40(Suppl. 1):1-142. 
17. National Institute for Health and Care Excellence. Type 2 diabetes in adults: management (NICE guideline 28). 2017 www.nice.org.uk/ guidance/ng28 (accessed 2 Aug 2017).

18. Tonstad S. Cigarette smoking, smoking cessation, and diabetes. Diabetes Res Clin Pract 2009;85:4-13.

19. Twardella D, Loew M, Rothenbacher D, et al. The diagnosis of a smoking-related disease is a prominent trigger for smoking cessation in a retrospective cohort study. J Clin Epidemiol 2006;59:82-9.

20. Centers for Disease Control and Prevention (CDC). Quitting smoking among adults--United States, 2001-2010. MMWR Morb Mortal Wkly Rep 2011;60:1513-9.

21. Agaku IT, King BA, Dube SR, et al. Current cigarette smoking among adults - United States, 2005-2012. MMWR Morb Mortal Wkly Rep 2014;63:29-34.

22. Gilmore J. Report on smoking in Canada 1985 to 2001: Statistics Canada. 2002 www.statcan.ca/english/research/82F0077XIE/ 82F0077XIE2001001.pdf (accessed 2 Aug 2017).

23. OECD. Health at a glance 2013: OECD indicators. Paris, France: OECD publishing, 2013.

24. Khang YH, Lynch JW, Kaplan GA. Impact of economic crisis on cause-specific mortality in South Korea. Int J Epidemiol 2005;34:1291-301.

25. Ueshima H, Sekikawa A, Miura K, et al. Cardiovascular disease and risk factors in Asia. Circulation 2008;118:2702-9.

26. Zhou X, Nonnemaker J, Sherrill B, et al. Attempts to quit smoking and relapse: factors associated with success or failure from the ATTEMPT cohort study. Addict Behav 2009;34:365-73.

27. Caponnetto P, Polosa R. Common predictors of smoking cessation in clinical practice. Respir Med 2008;102:1182-92.

28. Siahpush M, Borland R, Scollo M. Factors associated with smoking cessation in a national sample of Australians. Nicotine Tob Res 2003;5:597-602

29. Hyland A, Borland R, Li Q, et al. Individual-level predictors of cessation behaviours among participants in the International Tobacco Control (ITC) Four Country Survey. Tob Control 2006;15(Suppl 3):iii83-94.

30. Vangeli E, Stapleton J, Smit ES, et al. Predictors of attempts to stop smoking and their success in adult general population samples: a systematic review. Addiction 2011;106:2110-21.

31. Li L, Borland R, Yong HH, et al. Predictors of smoking cessation among adult smokers in Malaysia and Thailand: findings from the International Tobacco Control Southeast Asia Survey. Nicotine Tob Res 2010;12(Suppl 1):S34-44.

32. Lee $\mathrm{YH}, \mathrm{Han} \mathrm{K}, \mathrm{Ko} \mathrm{SH}$, et al. Data analytic process of a nationwide population-based study using national health information database established by national health insurance service. Diabetes Metab J 2016;40:79-82.
33. Kim L, Sakong J, Kim Y, et al. Developing the Inpatient Sample for the National Health Insurance Claims Data. Health Policy and Management 2013;23:152-61.

34. Song YM, Byeon JJ. Excess mortality from avoidable and non-avoidable causes in men of low socioeconomic status: a prospective study in Korea. J Epidemiol Community Health 2000;54:166-72.

35. Craig WY, Palomaki GE, Haddow JE. Cigarette smoking and serum lipid and lipoprotein concentrations: an analysis of published data. BMJ 1989;298:784-8.

36. Li L, Feng G, Jiang Y, et al. Prospective predictors of quitting behaviours among adult smokers in six cities in China: findings from the International Tobacco Control (ITC) China Survey. Addiction 2011;106:1335-45

37. Fidler JA, West R. Enjoyment of smoking and urges to smoke as predictors of attempts and success of attempts to stop smoking: a longitudinal study. Drug Alcohol Depend 2011;115:30-4.

38. West R, McEwen A, Bolling K, et al. Smoking cessation and smoking patterns in the general population: a 1-year follow-up. Addiction 2001;96:891-902.

39. Kim S-J, Ko K-D, Suh H-S, et al. Factors Associated with Intention to Quit Smoking in Korean Adult Males: The Sixth Korean National Health and Nutrition Examination Survey, 2013-2014. Korean Journal of Family Practice 2017;7:276-80.

40. Haire-Joshu D, Glasgow RE, Tibbs TL. Smoking and diabetes. Diabetes Care 2004;27(Suppl 1):s74-5.

41. Hagimoto A, Nakamura M, Morita T, et al. Smoking cessation patterns and predictors of quitting smoking among the Japanese general population: a 1-year follow-up study. Addiction 2010;105:164-73.

42. Long AN, Dagogo-Jack S. Comorbidities of diabetes and hypertension: mechanisms and approach to target organ protection. $J$ Clin Hypertens 2011;13:244-51.

43. Raherison C, Marjary A, Valpromy B, et al. Evaluation of smoking cessation success in adults. Respir Med 2005;99:1303-10.

44. Kim HE, Song YM, Kim BK, et al. Factors associated with persistent smoking after the diagnosis of cardiovascular disease. Korean J Fam Med 2013;34:160-8.

45. Chandola T, Head J, Bartley M. Socio-demographic predictors of quitting smoking: how important are household factors? Addiction 2004;99:770-7.

46. Huxley RR, Woodward M. Cigarette smoking as a risk factor for coronary heart disease in women compared with men: a systematic review and meta-analysis of prospective cohort studies. Lancet 2011;378:1297-305. 